\title{
Feature Size Modulation in Dewetting of Nanoparticle Containing Ultrathin Polymer Films
}

\author{
Anuja Das and Rabibrata Mukherjee*
}

Instability and Soft Patterning Laboratory, Department of Chemical Engineering, Indian Institute of Technology Kharagpur, Kharagpur 721302, WB, INDIA.

E-mail id: rabibrata@che.iitkgp.ac.in

\section{Electronic Supporting Information}

S1. Ascast morphologies of PS thin film:
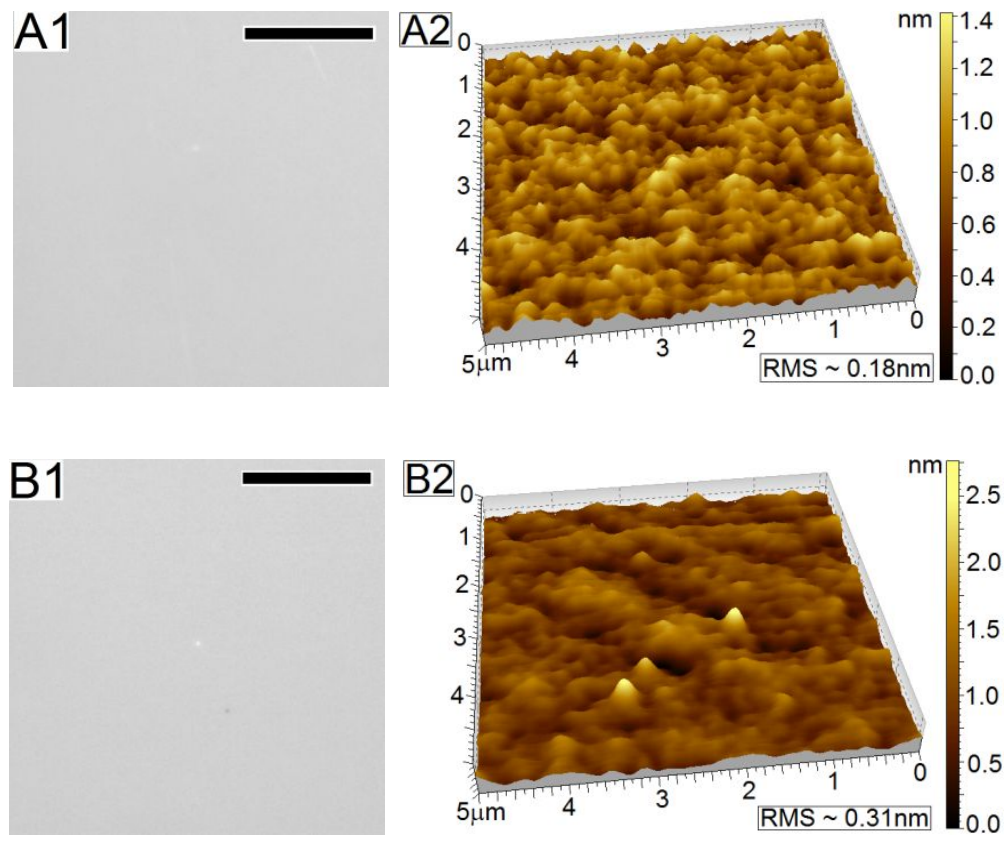

Figure S1. (A1, B1) Optical Micrographs and (A2, B2) AFM images of ascast morphology of PS thin film, having $\boldsymbol{h}_{F}=12 \mathrm{~nm},(\mathbf{A 1}, \mathbf{B 1})$ without AuNPs $\left(\boldsymbol{C}_{N P}=0.00 \%\right)$; and $(\mathbf{A 2}, \mathbf{B 2}) \boldsymbol{C}_{N P}=0.50 \%$ AuNPs. Scale bar in the OM images represents $20 \mu \mathrm{m}$ 


\section{S2. Calculation of polymer intrinsic viscosity using Mark-Houwink-Sakurada Equation:}

Intrinsic viscosity of polymer is a measure of polymer's contribution to the solution viscosity. It is typically calculated using the relation: $[\boldsymbol{\eta}]=\lim _{c \rightarrow 0} \frac{\eta-\eta_{0}}{\eta_{0} \cdot c}$, where $\boldsymbol{\eta}=$ dynamic or kinematic viscosity of the solution $\left(\mathrm{Pa}-\mathrm{s}\right.$ or $\left.\mathrm{m}^{2} / \mathrm{s}\right) ; \boldsymbol{\eta}_{\mathbf{0}}=$ viscosity in absence of polymer $\left(\mathrm{Pa}-\mathrm{s} \mathrm{or} \mathrm{m}^{2} / \mathrm{s}\right) ; \boldsymbol{c}=$ polymer mass concentration in practical setting $(\mathrm{g} / \mathrm{mL})$ and unit of polymer intrinsic viscosity $[\boldsymbol{\eta}]$ is $\mathrm{mL} / \mathrm{g}$.

Polymer intrinsic viscosity using Mark-Houwink-Sakurada Equation ${ }^{1}$ is calculated using the relation with appropriate values of $\mathbf{K}$ and $\mathbf{a}$ as mentioned below:

$$
[\boldsymbol{\eta}]=\boldsymbol{K} \boldsymbol{M}^{\boldsymbol{a}}
$$

Where, $\mathbf{K}=7.16 \times 10-3 \mathrm{~mL} / \mathrm{g} ; \mathrm{M}=$ Molecular weight $(\mathrm{g} / \mathrm{mol}) ; \mathbf{a}=0.760^{1}$ [for M range of 115,00 $\left.-2.8 \times 10^{6} \mathrm{~g} / \mathrm{mol}\right]$

Using equation 1 , we get polymer intrinsic viscosity as $[\boldsymbol{\eta}]=98.8 \mathrm{~mL} / \mathrm{g}$ for Polysytrene (PS) with molecular weight, $\mathrm{M}=280,000 \mathrm{Da}$ at $25^{\circ} \mathrm{C}$.

\section{S3. Calculation of PS melt viscosity at different temperatures:}

Calculation of polymer melt viscosity at $160^{\circ} \mathrm{C}:{ }^{2}$

$\log \boldsymbol{\eta}_{\mathbf{2 1 7}}=3.4\left(\log \boldsymbol{M}_{\boldsymbol{w}}\right)-13.40$, for $\boldsymbol{M}_{\boldsymbol{n}}>50,000 \ldots \ldots$ (2)

$\log \left(\frac{\boldsymbol{\eta}_{T}}{\boldsymbol{\eta}_{\mathbf{2 1 7}}}\right)=2.92 \times 10^{16}\left(\frac{1}{T^{6}}-\frac{1}{490^{6}}\right) e^{-\frac{2530}{M_{\boldsymbol{w}}}}$

Where $\mathrm{T}=$ temperature at which viscosity is calculated in Kelvin; $\boldsymbol{M}_{\boldsymbol{w}}=$ molecular weight of PS. Using equations 2 and 3 , PS melt viscosity, at $160^{\circ} \mathrm{C}$, is found to be $\approx 2.77 \times 10^{7} \mathrm{~Pa}$-s.

Similarly using equation 2 and 3, we could calculate the temperature at which PS melt viscosity is $\approx 9.68 \times 10^{6} \mathrm{~Pa}-\mathrm{s}$, which is $\approx 170^{\circ} \mathrm{C}$. 


\section{S4. Derivation of $\boldsymbol{t}_{\boldsymbol{m}}$ from Fick's Second Law of Diffusion:}

Concentration profile as derived from Fick's Second Law of Diffusion ${ }^{3}$ is

$$
c(x, t)=\frac{M}{\sqrt{4 \pi D t}} e^{\frac{-x^{2}}{4 D t}}
$$

Taking time derivative of concentration profile at a specific constant $\mathbf{x}$ we get,

$$
\begin{gathered}
\frac{d c}{d t}=\frac{d}{d t}\left[\frac{M}{\sqrt{4 \pi D t}} e^{\frac{-x^{2}}{4 D t}}\right] \\
=\frac{M}{\sqrt{4 \pi D t}} \cdot \frac{d}{d t}\left[e^{\frac{-x^{2}}{4 D t}}\right]+e^{\frac{-x^{2}}{4 D t}} \cdot \frac{d}{d t}\left[\frac{M}{\sqrt{4 \pi D t}}\right] \\
=\left(\frac{M}{\sqrt{4 \pi D t}} \cdot \frac{-1 / 2}{t}\right) \cdot e^{\frac{-x^{2}}{4 D t}}+\left(\frac{M}{\sqrt{4 \pi D t}}\right)\left[(-1) \cdot\left(\frac{-x^{2}}{4 D t^{2}}\right) \cdot e^{\frac{-x^{2}}{4 D t}}\right]
\end{gathered}
$$

For calculation of time $\left(\boldsymbol{t}_{\boldsymbol{m}}\right)$ required to reach maximum concentration at a specific distance $x$, we set time derivative of concentration profile to zero, as shown below:

$$
\begin{gathered}
\frac{d c}{d t_{x}=\text { constant }}=0 \\
\left(\frac{M}{\left.\sqrt{4 \pi D t} \cdot \frac{1}{t}\right) \cdot e^{\frac{-x^{2}}{4 D t}}}=\left(\frac{M}{\sqrt{4 \pi D t}}\right)\left[(-1) \cdot\left(\frac{-x^{2}}{4 D t^{2}}\right) \cdot e^{\frac{-x^{2}}{4 D t}}\right]\right. \\
\Rightarrow \frac{1 / 2}{t}=\frac{x^{2}}{4 D t^{2}} \\
\Rightarrow 1=\frac{x^{2}}{2 D t} \\
\Rightarrow \boldsymbol{t}_{\boldsymbol{m}}=\frac{x^{2}}{2 D} \ldots \ldots \ldots . .5
\end{gathered}
$$

\section{S5. Calculation of $t_{m}$ for Chloroform in Polystyrene:}

In order to calculate the time required by chloroform vapors to reach the substrate surface, following which dewetting is triggered in PS thin films, it is important to understand the diffusivity of solvent vapor molecules through entangled polymer chains. In the following section we calculate the approximate time required, using the expression obtained in equation 5, by vapors of chloroform to reach its maximum concentration at the surface of the substrate. To simplify the 
complex phenomenon of chloroform vapors diffusing through PS chains, we have considered certain assumptions (mentioned in the following section), to the best our knowledge, which would closely resemble this particular system.

Diffusion coefficient (D, in saturated chloroform vapor environment at $\left.25^{\circ} \mathrm{C}\right)=0.024 \times 10^{-10}$ $\mathrm{cm}^{2} / \mathrm{sec}^{4}$ Vapor Pressure of $\mathrm{CHCl}_{3}$ using Antoine Equation ${ }^{5}$ at $25^{\circ} \mathrm{C}=194.75 \mathrm{mmHg}$

\section{Assumptions:}

1. The system is considered to obey Fickian Diffusion.

2. Interaction between Chloroform and PS chains has not been considered while determining $\boldsymbol{t}_{\boldsymbol{m}}$

3. Immediate penetration of chloroform molecules i.e., induction time, as referred in Hui et. al., ${ }^{6}$ is considered to be $=0$.

4. Continuous change in diffusivity and viscosity, due to swelling of polymers by vapors of organic solvent, have not been considered. This has been experimentally determined by depth profiling using Rutherford Backscattering Spectrometry. ${ }^{4,6}$ Instead, the value of $\mathbf{D}$ is an average diffusion coefficient that has been experimentally determined by Crank et al. ${ }^{4}$ Therefore, to determine the time $\left(\boldsymbol{t}_{\boldsymbol{m}}\right)$ required for chloroform vapors to reach its maximum concentration near the substrate surface, we have considered $\boldsymbol{x}=$ film thickness $\left(\boldsymbol{h}_{\boldsymbol{F}}\right)$ and $\mathbf{D}=0.024$ x $10^{-10} \mathrm{~cm}^{2} / \mathrm{sec}$. Putting these values in equation 6 , we obtain $\boldsymbol{t}_{\boldsymbol{m}}=6.30 \mathrm{~s}$, for $\boldsymbol{x}=55 \mathrm{~nm}$ (film thickness).

Similarly, we have calculated $\boldsymbol{t}_{\boldsymbol{m}}$ for all film thicknesses $\left(\boldsymbol{h}_{\boldsymbol{F}}=12 \mathrm{~nm}, 20 \mathrm{~nm}, 38 \mathrm{~nm}\right.$ and $\left.55 \mathrm{~nm}\right)$ which are shown in table R1.

Table R1. Approximated time required for vapors of chloroform to reach maximum concentration near the substrate.

\begin{tabular}{|c|c|}
\hline Thickness (nm) & Diffusion time $\left(\boldsymbol{t}_{\boldsymbol{m}}, \mathbf{s e c}\right)$ \\
\hline 12 & 0.30 \\
\hline 20 & 0.83 \\
\hline 38 & 3.00 \\
\hline 55 & 6.30 \\
\hline
\end{tabular}




\section{S6. Calculation of interfacial energies between different components:}

In order to calculate the interfacial energies between different components, individual surface tension components $\left(\boldsymbol{\gamma}_{\mathbf{i}}^{\mathbf{L W}}, \boldsymbol{\gamma}_{\mathbf{i}}^{\mathbf{A B}}, \boldsymbol{\gamma}_{\mathbf{i}}^{+}\right.$and $\left.\boldsymbol{\gamma}_{\mathbf{i}}^{-}\right)$for each entity are required. For determining the $\boldsymbol{\gamma}^{\mathbf{L W}}$ , $\boldsymbol{\gamma}^{+}$and $\boldsymbol{\gamma}^{-}$for the substrate (silicon covered with native oxide layer), three probing liquids (Water, Ethylene Glycol, Diiodomethane) are chosen based on the fact that their individual components of surface tension are known, the values of which are listed in table R2.

Table R2. Surface tension component of probing liquids

\begin{tabular}{|c|c|c|c|c|c|}
\hline \multirow{2}{*}{ Probing Liquid } & \multicolumn{5}{|c|}{ Surface Tension Components $\left(\mathbf{m J} / \mathbf{m}^{\mathbf{2}}\right)$} \\
\cline { 2 - 6 } & $\begin{array}{c}\text { Dispersive } \\
\left.\boldsymbol{\gamma}_{\mathbf{i}}^{\mathbf{L W}}\right)\end{array}$ & $\begin{array}{c}\text { Acid } \\
\left(\boldsymbol{\gamma}_{\mathbf{i}}^{+}\right)\end{array}$ & Base $\left(\boldsymbol{\gamma}_{\mathbf{i}}^{-}\right)$ & $\begin{array}{c}\text { Polar } \\
\left(\boldsymbol{\gamma}_{\mathbf{i}}^{\mathbf{A B}}\right)\end{array}$ & $\begin{array}{c}\text { Total } \\
\left(\boldsymbol{\gamma}_{\mathbf{i}}\right)\end{array}$ \\
\hline $\begin{array}{c}\text { Ethylene Glycol } \\
(\mathrm{ETG})^{7}\end{array}$ & 21.8 & 25.5 & 25.5 & 21.8 & 72.8 \\
\hline Diiodomethane $^{7}$ & 50.42 & 0.72 & 0.48 & 19 & 48 \\
\hline
\end{tabular}

Table R3. Contact Angle Data of three probing liquids.

\begin{tabular}{|c|c|c|c|}
\hline Material & $\begin{array}{c}\text { Water } \\
\left(\theta_{\mathrm{E}-\mathrm{W}}{ }^{\circ}\right)\end{array}$ & $\begin{array}{c}\text { Ethylene Glycol } \\
\left(\theta_{\mathrm{E}-\mathrm{ETG}}{ }^{\circ}\right)\end{array}$ & $\begin{array}{c}\text { Toluene } \\
\left(\boldsymbol{\theta}_{\mathrm{E}-\mathrm{T}}{ }^{\circ}\right)\end{array}$ \\
\hline $\begin{array}{c}\text { Substrate (silicon } \\
\text { covered with native } \\
\text { oxide layer) }\end{array}$ & 3 & 5 & 2 \\
\hline
\end{tabular}

Contact angle for each liquid is used to calculate $\boldsymbol{\gamma}_{\mathbf{i}}^{\mathbf{L W}}, \boldsymbol{\gamma}_{\mathbf{i}}^{+}, \boldsymbol{\gamma}_{\mathbf{i}}^{-}$from Young-Dupre Equation given below (equation 6), and the calculated values are given in Table R4.

$\gamma_{\mathrm{L}}\left(\cos \theta_{\mathrm{E}}+\mathbf{1}\right)=2\left[\sqrt{\gamma_{\mathrm{i}}^{\mathrm{LW}} \boldsymbol{\gamma}_{\mathrm{L}}^{\mathrm{LW}}}+\sqrt{{\gamma_{\mathrm{i}}^{+} \gamma_{\mathrm{L}}^{-}}_{1}}+\sqrt{{\gamma_{\mathrm{i}}^{-} \gamma_{\mathrm{L}}^{+}}^{+}}\right]$

For every probing liquids $\gamma_{\mathbf{L}}^{\mathbf{L W}}, \gamma_{\mathbf{L}}^{+}$and $\gamma_{\mathbf{L}}^{-}$are known. So, with three probing liquids we get three linear simultaneous equations which, on solving, give the values of $\boldsymbol{\gamma}_{\mathbf{i}}^{\mathbf{L W}}, \boldsymbol{\gamma}_{\mathbf{i}}^{+}$and $\boldsymbol{\gamma}_{\mathbf{i}}^{-}$. The obtained values for the substrate are listed in Table R4. The values of $\boldsymbol{\gamma}_{\mathbf{i}}^{\mathbf{L W}}, \boldsymbol{\gamma}_{\mathbf{i}}^{+}$and $\boldsymbol{\gamma}_{\mathbf{i}}^{-}$for PS, $\mathrm{CHCl}_{3}$ and thiol (AuNPs) have been taken from the literature.

Table R4. Compiled value of individual component of surface tension for different materials. 


\begin{tabular}{|c|c|c|c|c|c|}
\hline \multirow[t]{2}{*}{ Material } & \multicolumn{5}{|c|}{ Individual components of Surface Tension $\left(\mathrm{mJ} / \mathrm{m}^{2}\right)$} \\
\hline & $\gamma_{i}^{L W}$ & $\gamma_{i}^{+}$ & $\gamma_{\mathrm{i}}^{-}$ & $\gamma_{\mathbf{i}}^{\mathrm{AB}}$ & $\gamma_{\mathrm{i}}$ \\
\hline Substrate & 49.9 & 2.0 & 86.4 & 26.5 & 76.5 \\
\hline $\mathrm{PS}^{7}$ & 40.1 & 0 & 1.1 & 0 & 40.1 \\
\hline $\mathrm{CHCl}_{3}{ }^{9}$ & 27.2 & 1.5 & 0 & 0 & 27.7 \\
\hline Thiol (AuNPs) ${ }^{10}$ & 30.0 & 0 & 1.3 & 0 & 30.0 \\
\hline
\end{tabular}

Where, $\boldsymbol{\gamma}_{\mathbf{i}}=\boldsymbol{\gamma}_{\mathrm{i}}^{\mathrm{LW}}+\boldsymbol{\gamma}_{\mathbf{i}}^{\mathrm{AB}}$ (6) and $\boldsymbol{\gamma}_{\mathbf{i}}^{\mathbf{A B}}=\mathbf{2}\left(\sqrt{{\gamma_{\mathbf{i}}^{+} \boldsymbol{\gamma}_{\mathbf{i}}^{-}}^{-}}\right)$

Calculation of interfacial energies from the following equation: ${ }^{7}$

$\gamma_{12}=\gamma_{1}+\gamma_{2}-2\left(\sqrt{\gamma_{1}^{\mathrm{LW}} \cdot \gamma_{2}^{\mathrm{LW}}}+\sqrt{\gamma_{1}^{+} \cdot \gamma_{2}^{-}}+\sqrt{\gamma_{1}^{-} \cdot \gamma_{2}^{+}}\right) \ldots \ldots \ldots(8)$

Table R5. Calculated interfacial energies among substrate, $\mathrm{PS}$ and $\mathrm{CHCl}_{3}$ and thiol (AuNPs)

\begin{tabular}{|c|c|}
\hline Interfacial energy & $\gamma_{12}\left(\mathrm{~mJ} / \mathrm{m}^{2}\right)$ \\
\hline Substrate $-\mathrm{PS}\left(\gamma_{\mathrm{S}-\mathrm{PS}}\right)$ & 24.16 \\
\hline $\mathrm{PS}-($ thiol$) \mathrm{AuNP}\left(\gamma_{\mathrm{PS}-\mathrm{NP}}\right)$ & 0.73 \\
\hline Substrate $-\mathrm{CHCl}_{3}\left(\gamma_{\mathrm{S}-\mathrm{CHCl} 3}\right)$ & 7.76 \\
\hline $\mathrm{PS}-\mathrm{CHCl}_{3}\left(\gamma_{\mathbf{P S}-\mathrm{CHCl3}}\right)$ & 1.24 \\
\hline Substrate $-($ thiol$) \mathrm{AuNP}\left(\gamma_{\mathrm{S}-\mathrm{NP}}\right)$ & 9.62 \\
\hline
\end{tabular}




\section{S7. Morphological evolution of $12 \mathrm{~nm}$ thick PS film on thermal annealing at $160^{\circ} \mathrm{C}$ :}

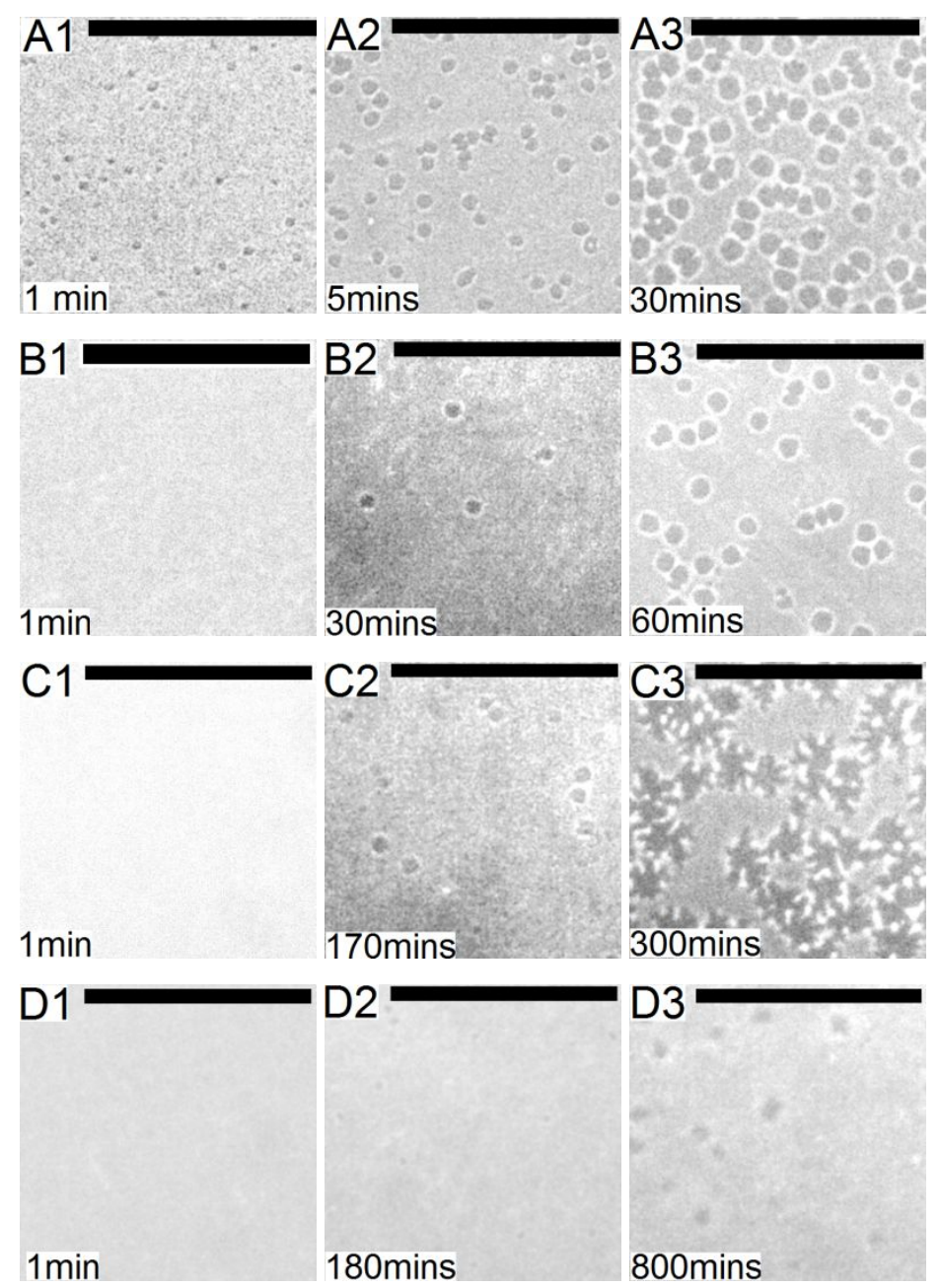

Figure S2. Optical Micrographs showing the morphological evolution of $12 \mathrm{~nm}$ thick PS film on thermal annealing at $160{ }^{\circ} \mathrm{C}$ over time for $\boldsymbol{C}_{\boldsymbol{N P}}=(\boldsymbol{A 1}-\boldsymbol{A 3}) 0.00 \%$ AuNPs; $(\boldsymbol{B} 1-\boldsymbol{B} 3) 0.50 \% ;(\boldsymbol{C} \boldsymbol{1}$ - C3) 1.00\%; (D1 - D3) 5.00\% AuNPs. Scale bar represents $20 \mu \mathrm{m}$.

\section{S8. Calculation of Flory Huggin's Interaction $(\chi)$ Parameter:}

To understand how solvent penetration alters the interaction between PS, AuNP and the substrate during SVE, we have calculated Flory Huggin's Interaction $(\chi)$ Parameter for different pair of components such as polymer-solvent, polymer-nanoparticles and solvent-nanoparticles. The magnitude of $\chi$ parameter helps in determining whether mixing of two components is thermodynamically favored or not, and in case where they are favored it indicates to the extent of their miscibility. For a specific pair, miscibility depends on the critical chi parameter $\left(\chi_{c r}\right)$, which depends on the nature of the interacting species. For polymer - polymer $\chi_{c r} \approx 0$, whereas for polymer - solvent interaction $\chi_{c r} \approx 0.5 .{ }^{11}, 12$ Further Lohman et. al has formalized that a 
nanoparticle comprising of a metallic core to which a ligand is attached as a flexible polymer tethered chain for the purpose of free energy calculation and interparticle distance. ${ }^{13}$ Therefore, interaction between PS - thiol (AuNPs) is taken to be as polymer - polymer interaction while thiol (AuNPs) - chloroform to have polymer - solvent type interaction. We have calculated $\chi$ parameter using Hildebrand's Solubility Parameter ${ }^{14,15}$ for each interaction and determined the miscibility between two components by comparing with respective $\chi_{c r}$, which are listed in table R7.

Table R6. Table showing values of Hildebrand's Solubility Parameters for each component in the blend solution

\begin{tabular}{|c|c|c|c|c|}
\hline $\begin{array}{c}\text { Hildebrand's } \\
\text { Solubility Parameter } \\
\left(\mathrm{cal}^{-1 / 2} \mathrm{~cm}^{-3 / 2}\right)\end{array}$ & Thiol $^{14}$ & Toluene $^{16}$ & PS $^{16}$ & Chloroform $^{17}$ \\
\hline $\boldsymbol{\delta}$ & 7.9 & 8.9 & 9.1 & 9.3 \\
\hline
\end{tabular}

Table R7. Flory Huggin's Interaction Parameter for each pair of components.

\begin{tabular}{|c|c|c|c|c|}
\hline $\begin{array}{c}\text { Interaction } \\
\text { Type }\end{array}$ & $\begin{array}{c}\text { Nature of } \\
\text { Interaction }\end{array}$ & $\chi_{c r}$ & $\begin{array}{c}\text { Flory } \\
\text { Huggin's } \\
\text { Interaction } \\
\text { Parameter, } \\
\chi_{12}\end{array}$ & Miscibility \\
\hline $\begin{array}{c}\text { PS- thiol } \\
\text { (AuNPs) }\end{array}$ & $\begin{array}{c}\text { Polymer - } \\
\text { Polymer }\end{array}$ & 0.0 & 0.555 & Immiscible \\
\hline $\begin{array}{c}\text { PS-CHCl }_{3} \\
\text { Solvent - } \\
\text { Polymer }\end{array}$ & 0.5 & 0.345 & Miscible \\
\hline $\begin{array}{c}\mathrm{CHCl}_{3^{-}} \\
\text {thiol } \\
\text { (AuNPs) }\end{array}$ & $\begin{array}{c}\text { Solvent - } \\
\text { Polymer }\end{array}$ & 0.5 & 0.607 & Immiscible \\
\hline $\begin{array}{c}\text { Toluene - } \\
\text { thiol } \\
\text { (AuNPs) }\end{array}$ & $\begin{array}{c}\text { Solvent - } \\
\text { Polymer }\end{array}$ & 0.5 & 0.442 & Miscible \\
\hline
\end{tabular}

As an example, the calculation of $\chi$ for PS and Chloroform is shown below:

$$
\chi_{P S-C H C l 3}=\frac{V_{r}}{R T}\left(\partial_{1}-\partial_{2}\right)^{2}+0.34
$$

$\mathbf{V}_{\mathbf{r}}=$ Molar volume of Chloroform is taken as $80.7 \mathrm{c} . \mathrm{c} / \mathrm{mole}^{18}{ }^{18} \mathbf{R}=1.872 \mathrm{cal} \mathrm{mol}^{-1} \mathrm{~K}^{-1}, \mathbf{T}=298 \mathrm{~K}$ and taking $\delta$ as mentioned in Table R6, $\boldsymbol{\delta}_{\mathrm{PS}}=9.1 \mathrm{cal}^{-1 / 2} \mathrm{~cm}^{-3 / 2}$ and $\delta_{\mathrm{CHCl}}=9.3 \mathrm{cal}^{-1 / 2} \mathrm{~cm}^{-3 / 2}$, we obtain: 


$$
\boldsymbol{X P S}-\boldsymbol{C H C l 3}=\frac{80.7\left(\frac{\mathrm{cm}^{3}}{\mathrm{~mole}}\right)}{1.9872\left(\frac{\mathrm{cal}}{K . \text { mole }}\right) \times 298(\mathrm{~K})}(9.3-9.1)^{2}+0.34 \quad\left(\mathrm{cal}^{-\frac{1}{2}} \cdot \mathrm{cal}^{-\frac{3}{2}}\right)^{2}=0.345
$$

$\chi_{P S-C H C l 3}<0.5\left(\chi_{c r}\right)$ for polymer - solvent interaction, proving miscibility between PS and $\mathrm{CHCl}_{3}$. Similarly, all the $\chi$ values listed in table R7 were obtained by the above shown method of calculation and the nature of interactions were determined by comparing the calculated $\chi$ value with the respective $\chi_{c r}$. Calculated values of $\chi$ shown in table R5 suggests that thiol capped AuNP is incompatible with either of PS and $\mathrm{CHCl}_{3}$ and therefore is mostly non-interacting. Additionally, since $\chi$ parameter for PS and chloroform is less than 0.5 , it indicates to miscibility between polymer and solvent. Hence, addition of AuNPs does not significantly alter any existing interactions between $\mathrm{PS}, \mathrm{CHCl}_{3}$ as particles are mostly non-interacting.

\section{References:}

1. Wagner, H. L. The Mark-Houwink-Sakurada Equation for the Viscosity of Atactic Polystyrene. J. of Phys. Chem. Ref. Data 1985, 14, 1101 - 1106.

2. Fox, T. G.; P. J. Flory. Further studies on the melt viscosity of polyisobutylene. J. Phys. Colloid Chem. 1951, 55, $221-234$.

3. Treybal, R. E. Mass Transfer Operations International Edition 1981, McGraw Hill Chemical Engineering Series.

4. Crank. J.; Park, G. S. An evaluation of the diffusion coefficient for chloroform in polystyrene from simple absorption experiments. Trans. Faraday Soc. 1949, 45, 240 $-249$.

5. Yaws, C. L.; Yang, H. C. To estimate vapor pressure easily. Hydrocarbon Processing 1989, $68,65-68$.

6. Hui, C.-Y.; Wu, K.-C. Case-II diffusion in polymers. I. Transient swelling. J. Appl. Sc. 1987, $61,5129-5136$. 
7. Roy, S.; Bandyopadhyay, D.; Karim, A.; Mukherjee, R. Interplay of Substrate Surface Energy and Nanoparticle Concentration in Suppressing Polymer Thin Film Dewetting. Macromolecules 2015, 48, 2, 373 - 382.

8. Janczuk, B.; Wojcik, W.; Zdziennicka, A. Determination of the components of the surface tension of some liquids from interfacial liquid-liquid tension measurements. J. Colloid Interface Sci. 1993, 157, $384-393$.

9. https://www.accudynetest.com/surface_tension_table.html

10. U.S. Coast Guard, Department of Transportation. CHRIS - Hazardous Chemical Data. Volume II. Washington, D.C.: U.S. Government Printing Office, 1984-5.

11. Robeson, L. M. POLYMER BLENDS: A Comprehensive Review, Carl Hanser Verlag GmbH \& Co. KG, 2007.

12. Patterson, D.; Robard, A. Thermodynamics of Polymer Compatibility. Macromolecules 1978, 11, $690-695$.

13. Lohman, B. C.; Powell, J. A.; Cingarapu, S.; Aakeroy, C. B.; Chakrabarti, A.; Klabunde, K. J.; Law, B. M.; Sorensen, C. M. Phys. Chem. Chem. Phys. 2012, 14, 6509.

14. Hajiw, S.; Schmitt, J.; Impéror-Clerca, M.; Pansu, B. Solvent-driven interactions between hydrophobically-coated nanoparticles. Soft Matter 2015, 11, 3920 - 3926.

15. Fekete, E.; Foldes, E.; Damsits, F.; Pukanszky, B. Interaction-structure-property relationships in amorphous polymer blends. Polymer Bulletin 2000, 44, 363 - 370.

16. Bhandaru, N.; Karim, A.; Mukherjee, R. Directed ordering of phase separated domains and dewetting of thin polymer blend films on a topographically patterned substrate. Soft Matter 2017, 17, $4709-4719$.

17. Barton, A. F. M. Solubility parameters. Chem. Rev. 1975, 75, $731-753$.

18. Haynes, W.M. (ed.). CRC Handbook of Chemistry and Physics. 95th Edition. CRC Press L LC, Boca Raton: FL 2014-2015, p. 3-520. 